\title{
Comparison of two methods for factor five Leiden detection in patients with thromboembolism.
}

\author{
Mohammad Ghorbani ${ }^{1}$, Mohsen Hamidpour ${ }^{2 *}$, Mahmoud Reza Nematallahi ${ }^{3}$, Hamid Reza Niazkar ${ }^{4}$ \\ ${ }^{1}$ Department of Hematology and Blood Blanking, Gonabad University of Medical Sciences, Gonabad, Iran \\ ${ }^{2}$ Department of Hematology and Blood blanking, School of Allied Medical Science, Shahid Beheshti University of \\ Medical Sciences, Tehran, Iran \\ ${ }^{3}$ Cardiologist, Gonabad University of Medical Sciences, Gonabad, Iran \\ ${ }^{4}$ Student Research Committee, Gonabad University of Medical Sciences, Gonabad, Iran
}

\begin{abstract}
Introduction: Factor five Leiden is one of the most important hereditary risk factors for thrombotic events, especially in an early age and during pregnancy patients. Therefore, detection of the factor in the thrombotic events is one of the diagnostic priorities. We can detect this factor in the laboratory thorough two common tests such as Activated protein $\mathrm{C}$ resistance and molecular methods especially PCR-RFLP. In this study we evaluated the sensitivity and specificity of the APCR test in comparison of PCR-RFLP the golden diagnostic test for Factor Five Leiden.

Materials and methods: In this research, we have been studied fifty six patients with vascular thrombosis, who visited thrombosis clinical center in Imam Khomeini Hospital. After confirming the DVT diagnosis and pulmonary embolism, blood samples were collected in $3.2 \%$ sodium citrate tubes for APCR test, and in $\mathrm{K}_{2}$ EDTA CBC tubes for molecular tests.

Results: Fifty six DVT patients, including 26 males (44.6\%) and 30 females (55.4\%), from 1 year up to 50 years old with mean age of $28.9 \pm 10.76$ were studied. According to PCR-RFLP test out of the 56 patients, $15(26.7 \%)$ had heterozygous and $5(8.9 \%)$ homozygous mutation for factor $V$ Leiden. The very same 20 patients had positive APCR results (Rate of less than 2 and time less than 120 seconds were considered positive), in conclusion the results of the two tests were $100 \%$ compatible.

Discussion and conclusion: In populations where other mutations resistant to active protein $\mathrm{C}$ such as factor V Cambridge, $\mathbf{R} 2$ polymorphism and factor $\mathrm{V}$ Liverpool have low prevalence, by removing the intervening factors such as Lupus Anticoagulant antibody, the APCR test could be considered equally sensitive and specific as PCR-RFLP test and can be used for factor $V$ Leiden detection by spending less time and money.
\end{abstract}

Keywords: Factor V Leiden, APCR, PCR-RFLP method, Venous thrombosis.

Accepted on February 22, 2018

\section{Introduction}

The Vein Thrombosis (VTE) encompasses Deep Vein Thrombosis (DVT) and Pulmonary Embolism (PE) [1]. Risk factors for VTE are classified into genetical and acquired [2]. Genetic risk factors are including: quantitative or qualitative abnormalities of protein $\mathrm{C}$, protein $\mathrm{S}$, anti-thrombin III [3]. The second group of mutations consists of those that raise the level of pro-thrombotic proteins e.g. Factor $V$ Leiden mutation, prothrombin gene mutation (G20210A) and MTHFR enzyme coding gene mutation which all cause thrombosis $[3,4]$.

Factor $V$ Leiden is the most common genetic risk factor for VTE with the prevalence of $20 \%$ to $25 \%$ and the prevalence of $50 \%$ for familial thrombophilia [5]. Although the most DVT patients have clinically silent signs and symptoms, but depending on the degree of obstruction and inflammation of the vessels, the symptoms can be evident. Since the mutation of Factor $V$ Leiden is one of the most common factors for Thrombophilia especially in young children and pregnant women, we should consider factor $V$ Leiden detecting tests in DVT patients. There are two common tests in laboratories for detection of factor $V$ Leiden mutation consisting of Activated Protein C Resistance (APCR) and molecular analysis and detection of the mutation by the use of restrictive enzymes, RFLP-PCR in particular [6]. Although PCR-RFLP is the Gold Standard test for detection of Factor $V$ Leiden mutation, it cannot be performed in any regular laboratory and its more expensive and time consuming than APCR test, we performed 
a study in order to evaluate APCR specificity and Sensitivity in comparison to PCR-RFLP test for detecting the FVL mutation in venous thrombosis and pulmonary embolism.

\section{Materials and Methods}

\section{Samples}

Of patients with definitive diagnosis of DVT and PE (according to Doppler sonography and clinical signs and symptoms) who were visited the thrombosis clinical center in Imam Khomeini hospital ((Tehran) during 2015-2016) we excluded the patients with the history of anticoagulant consumption such as Heparin and Warfarin, patients with prolonged Partial Prothrombin Time (PTT) and patients with positive Lupus Anticoagulant antibody (LAC) and we choose fifty six patients appropriate for our study. The participants gave informed consent in accordance with the Deceleration of Helsinki. Anticoagulant blood (sodium citrate 3.2\% and EDTA) were collected from all patients. Citrated samples were then centrifuges in $1200 \mathrm{~g}$ for $10 \mathrm{~min}$ and the Platelet Poor Plasma (PPP) was separated and kept in $-20^{\circ} \mathrm{C}$, though they were melted down in $37^{\circ} \mathrm{C}$ water bath prior to testing. APCR test was carried out according to the instructions of the respective kit (Stago APCR Kit built with STA Compact device made in French). Rate results of less than 2 and time less than $120 \mathrm{~s}$ were considered positive and rate of more than 2 and times over $120 \mathrm{~s}$ were considered normal.

Genomic DNA was isolated from blood samples using Sinaclone DNA extraction kit. Concentration and purity was determined using nanodrop in 260 and $280 \mathrm{nM}$. Primers with the sequences and amplified fragment lengths are mentioned in Table 1, purchased from invitrogen Company. For FV Leiden mutation, PCR micro tubes were prepared as follows: $2 \mu 1$ primer, $2 \mu 1$ genomic DNA, $12.5 \mu 1$ master mix and $8.5 \mu 1 \mathrm{DW}$. The tubes were put in thermo cycler with particular programs which are mentioned in Table 2. Afterwards, we used RFLP technique to determine the existence of the mutation and also whether the mutation is heterozygous or homozygous. MnlI enzyme (Invitrogen Company) was used for FVL. All the steps of the RFLP technique were conducted according to the purchased kit from invitrogen Company. After exposing the products of PCR to MnlI enzyme, we transferred the result of enzymatic products on agarose gel electrophoresis 2\%. Every steps of PCR-RFLP procedure were performed with the presence of positive and negative control for FVL mutation.

\section{Results}

Fifty six DVT patients, including 26 males (44.6\%) and 30 females $(55.4 \%)$, from 1 year up to 50 years old with mean age of $28.9 \pm 10.76$ were studied. According to PCR-RFLP test out of the 56 patients, $15(26.7 \%)$ had heterozygous and $5(8.9 \%)$ homozygous mutation for Factor $V$ Leiden. The very same 20 patients had positive APCR results. Results are listed in Tables 3 and 4 .
The length of the proliferated sequence for $\mathrm{F}$ V Leiden is 288 bp. RFLP was carried out for both detecting the mutation and determination of hetero- or homozygosity of the mutant individuals in which MnlI was used as a restriction enzyme. Because of the presence of slicing site in normal people, 130 $\mathrm{bp}$ and $158 \mathrm{bp}$ long sequences are yielded but in case of the mutation, due to lack of the slicing site the sequences are 288 bp long. As a result, all three 158 bp, 130 bp and 288 bp long sequences must be observed in heterozygous cases while in homozygous ones the only sequence is the $288 \mathrm{bp}$ (Figure 1).

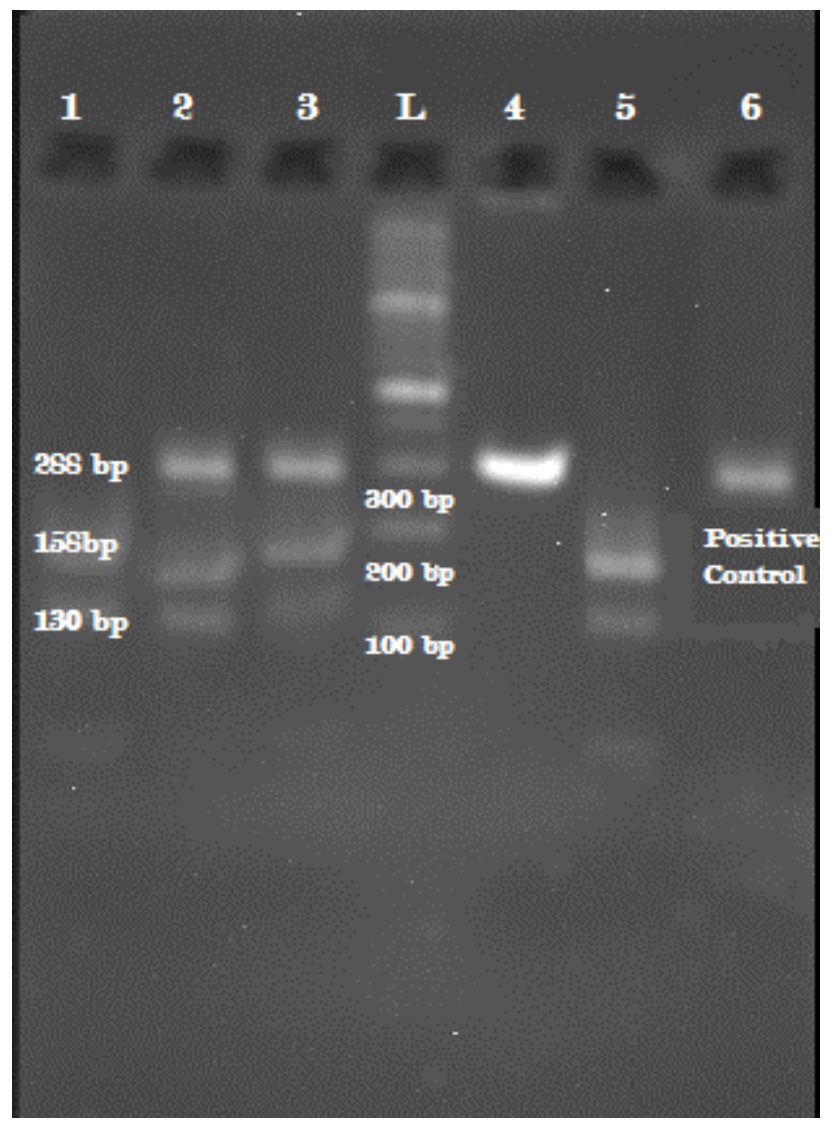

Figure 1. RFLP for factor $V$ Leiden by MnlI enzyme. After exposing the products of PCR with MnlI enzymes, in order to identify factor Five Leiden mutations and homozygous and heterozygous status, the result of enzymatic digestion products were transferred on agarose gel electrophoresis 2\%. Wells number 1 and 5: patients without the mutation of factor Five Leiden (158-130 bp). Wells number 2 and 3 . heterozygous patients for factor Five Leiden (288-158-130 bp). Well number 4: homozygous patient for the Factor Five Leiden. (288 bp); well number 6: Positive control for Factor $V$ Lieden mutation (Homozygous) (288 bp); L: DNA lader (100 bp).

Table 1. Primer sequence for F V Leiden.

\begin{tabular}{lll}
\hline Gene name & Primer sequence & $\begin{array}{l}\text { Amplified } \\
\text { fragment length }\end{array}$ \\
\hline F V Leiden & 5/GGAACAACACCATGATCAGACCA3/For & $288 \mathrm{bp}$ \\
\cline { 2 - 3 } & 5/TAGCCAGGAGACCTAACATGTTC3/Rev \\
\hline
\end{tabular}

Table 2. Thermocycle program for detection of factor V Leiden. 


\begin{tabular}{llll}
\hline Stage & Temperature $\left({ }^{\circ} \mathbf{C}\right)$ & Time $(\mathbf{s})$ & Cycle \\
\hline Initial denaturation & 95 & 120 & 1 \\
\hline Denaturation & 94 & 30 & 40 \\
\hline Anneling & 57 & 45 & 40 \\
\hline Extension & 72 & 45 & 40 \\
\hline Final extension & 72 & 360 & 1 \\
\hline
\end{tabular}

Table 3. APCR test result.

\begin{tabular}{lll}
\hline & APCR & \\
\cline { 2 - 3 } & Abnormal $(<\mathbf{1 2 0} \mathbf{~ s})$ & Normal $(>120 \mathbf{~ s})$ \\
\hline Patients & 20 & 36 \\
\hline Percentage & 35.7 & 64.3 \\
\hline Total & 56 & \\
\hline
\end{tabular}

Table 4. Prevalence of factor five Leiden on examined patients by RFLP method.

\begin{tabular}{|c|c|c|c|c|}
\hline $\begin{array}{l}\text { Mutation } \\
\text { name }\end{array}$ & $\begin{array}{l}\text { Total } \\
\text { patients }\end{array}$ & $\begin{array}{l}\text { Patients with FV } \\
\text { Lieden }\end{array}$ & $\begin{array}{l}\text { Heterozygot } \\
\text { e }\end{array}$ & $\begin{array}{l}\text { Homozygot } \\
\text { e }\end{array}$ \\
\hline $\begin{array}{l}\text { Factor five } \\
\text { Leiden }\end{array}$ & 56 & $20(35.7 \%)$ & $15(26.7 \%)$ & $5(8.9 \%)$ \\
\hline
\end{tabular}

\section{Discussion}

Since venous thrombosis is multi-factorial phenomenon, a precise detection of the cause of thrombophilia demands a thorough laboratory study on venous thrombosis patients [7]. Lubetsky and Seligsohn recommended APCR, LAC, Prothrombin G20210A, Homocysteine and factor VIII as the priority tests in detecting the cause of venous thrombosis [8].

Factor V Lieden is the most common hereditary risk factor for venous thrombosis. There is an irregular distribution of the mutation throughout the world. Africans, Americans, Asians and indigenous Australians do not have this mutation though it is observed in 5\% of White Americans, Canadians, and North Europeans and up to $15 \%$ in countries such as Sweden and Cyprus. For Asia, a $2.5 \%$ and $1.9 \%$ prevalence have been reported in Saudi Arabs and North Indians respectively [9].

Because of being multiracial and multicultural, Iranian population does not have a consistent figure of prevalence. In a study by Farokhi et al. on western population of Iran (304 patients), FVL mutation prevalence was $2.3 \%$ while another study on the population of the same region reported the figure to be $2.97 \%$ [10].

Due to its important effect on directing hemostasis towards coagulation which can result in thrombotic events particularly in young children and pregnant women and also its prevalence among populations, detecting FVL is undoubtedly one of the priorities for which APCR and molecular test are used.

APCR test is based on PTT and is a fraction in which numerator is PTT in the presence of APC and the denominator is PTT in the absence of APC. In normal individuals this ratio is above 2 while in those with the mutation is below 2 [11].

Due to the interfering factors such as LAC, heparin and deficiency of other coagulation factors, the first generation of APCR test did not have the required sensitivity and specificity. The second generation though, with the administration of polyberen to eliminate the effect of heparin and dilution of patient's plasma with FV-deficient plasma, is almost entirely sensitive and specific [11].

By carrying out both tests of APCR and PCR-RFLP on LACnegative patients with no history of anticoagulant drugs consumption such as heparin and comadin, we concluded that the APCR test can be equally specific and sensitive as PCRRFLP for our sample population. Of the fifty six studied patients, 20 had the mutation from which 15 (26.7\%) were heterozygous and $5(8.9 \%)$ homozygous. The very same 20 patients had positive APCR results (rate of below 2) and the results of the two tests were completely compatible.

Howard et al. conducted both the APCR and molecular tests on plasma of 117 patients with thrombosis where APCR test proved $100 \%$ accurate and molecular test, despite costing more, did not show any advantages over the other. It is notable that they have excluded the LAC-positive and anticoagulant consuming patients [12].

In study by Brain et al., where APCR test was carried out on plasma of 54 patients diagnosed with APS syndrome, 5 samples had an abnormal result (below 2 or below $120 \mathrm{~s}$ ) whose molecular tests did not detect the FVL mutation. These 5 samples were then diluted with FV-deficient plasma and while after reducing the titer by dilution, APCR result were normal. These patients had a lengthened PTT due to a high titer of inhibitors. This study showed that dilution with FV-deficient plasma eliminates the interference and the consequent overlap of the heterozygous individuals with normal ones [11].

However in a study by James et al., APCR test was reported $100 \%$ sensitive and specific in homozygotes. But the heterozygotes had a sensitivity of $50 \%$ and specificity of $98 \%$ because of overlap with normal individuals and due to this overlap, APCR rates of 2 to 3 need other confirming tests [6]. Nevertheless, this overlap is entirely eliminated by the means of dilution with FV-deficient plasma [13].

By taking the figure of 1.89 as cut-off for the APCR test in their study, Adriana $Z$ et al reported a sensitivity and specificity of 99.1 for it and considered it as a screening test alongside the molecular one being the definitive one. They also suggest simultaneous execution of the two tests in case of borderline results of APCR [14].

In cases where APCR results are lowered but the molecular ones are normal (lacking the mutation), we have to suspect liver and bone marrow transplant, defect of protein $\mathrm{C}$ and $\mathrm{S}$, elevated Factor VIII and other rare mutations of factor $\mathrm{V}$ such as factor $\mathrm{V}$ Cambridge, R2 polymorphism and factor $\mathrm{V}$ Liverpool all of which could result in lowered APCR [15-17]. 
Several common conditions can cause a false-positive outcome in APCR assay such as pregnancy, malignancy, use of Oral Contraceptives (OCPs), and hormone replacement therapy. In addition, the presence of lupus anticoagulants, anti-APC antibodies influences APC resistance tests [18].

\section{Conclusion}

According to our study by omitting intervening factors such as patients with LAC antibody, patients with anticoagulant consumption history and prolonged PTT, APCR results can be $100 \%$ sensitive and specific as the results were entirely in consistence with those of PCR-RFLP in patients with both homozygotes and heterozygotes FV Leiden mutation. According to previous studies, dilution of the sample with FVdeficient plasma can remove the effects of intervening factors especially Lupus anticoagulant. Molecular tests including PCR-RFLP are capable of detecting 10 to 20 percent of APCR lowered results due to mutations of factor $\mathrm{V}$ other than FVL since they are costly and time-consuming in populations where mutations such as factor V Cambridge, R2 polymorphism and factor $\mathrm{V}$ Liverpool have low prevalence, by removing the intervening factor and ruling out the acquired active protein $\mathrm{C}$ resistance conditions, the APCR test could be considered equally sensitive and specific as PCR-RFLP test for detection of factor $V$ Leiden mutations.

\section{Acknowledgements}

The authors would like to thank the Thrombosis research center of Imam Khomeini Hospital for supporting this project.

\section{Authorship and Conflict-of-Interest Statements}

The authors declare that they have no conflicts of interest. The Authors declare that they have analysed the data, performed the research and wrote the paper to review and final approval of the version to be published.

\section{References}

1. Rees DC, Cox M, Clegg JB. World distribution of factor V Leiden. Lancet 1995; 346: 1133-1134.

2. Lane DA, Mannucci PM, Bauer KA, Bertina RM, Bochkov NP, Boulyjenkov V, Chandy M, Dahlback B, Ginter EK, Miletich JP, Rosendaal FR, Seligsohn U. Inherited thrombophilia: Part 2. Thromb Haemost 1996; 76: 824-834.

3. Svensson PJ, Dahlback B. Resistance to activated protein C as a basis for venous thrombosis. N Engl J Med 1994; 330: 517-522.

4. Dahlback B. Resistance to activate protein C, the Arg506 to Gln mutation in the factor $\mathrm{V}$ gene, and venous thrombosis. Functional tests and DNA-based assays, pros and cons. Thromb Haemostasis 1995; 73: 739.

5. Dahlbäck B, Carlsson M, Svensson PJ. Familial thrombophilia due to a previously unrecognized mechanism characterized by poor anticoagulant response to activated protein $\mathrm{C}$ : prediction of a cofactor to activated protein $\mathrm{C}$. Proc Nat Acad Sci USA 1993; 90: 1004-1008.
6. Zehnder JL, Benson RC. Sensitivity and specificity of the APC resistance assay in detection of individuals with factor V Leiden. Am J Clin Pathol 1996; 106: 107-111.

7. Rosendaal FR. Venous thrombosis: a multicausal disease. Lancet 1999; 353: 1167-1173.

8. Seligsohn U, Lubetsky A. Genetic susceptibility to venous thrombosis. N Engl J Med 2001; 344: 1222-1231.

9. Jadaon MM. Epidemiology of activated protein $\mathrm{C}$ resistance and Factor $\mathrm{V}$ Leiden mutation in the Mediterranean Region. Mediterranean J Hematol Infect Dis $2011 ; 3$.

10. Pourgheysari B, Farrokhi E. Frequency of thrombophilia gene polymorphisms: factor $\mathrm{V}$ Leiden, prothrombin G20210A, methylenetetrahydrofolate-reductase and platelet PLA2 antigen in Shahrekord. Feyz J Kashan Univ Med Sci 2012; 16.

11. Ragland BD, Reed CE, Eiland BM, Tichenor PH, Hudson CL, Fritsma GA. The effect of lupus anticoagulant in the second-generation assay for activated protein $\mathrm{C}$ resistance. Am J Clin Pathol 2003; 119: 66-71.

12. Liebman HA, Sutherland D, Bacon R, McGehee W. Evaluation of a tissue factor dependent factor $\mathrm{V}$ assay to detect factor V Leiden: demonstration of high sensitivity and specificity for a generally applicable assay for activated protein C resistance. Br J Haematol 1996; 95: 550-553.

13. Andersson N, Andersson M, Andras M, Rosen S. High discrimination for FVQ506 also in OAC-patients, with COATEST (R) ACP (TM) resistance after predilution in FV-deficient plasma. Blood 1995.

14. Herskovits AZ, Morgan EA, Lemire SJ, Lindeman NI, Dorfman DM. An improved algorithm for activated protein $\mathrm{C}$ resistance and factor $\mathrm{V}$ Leiden screening. Am J Clin Pathol 2013; 140: 379-386.

15. Crookston KP, Henderson R, Chandler WL. False negative factor $\mathrm{V}$ Leiden assay following allogeneic stem cell transplant. Br J Haematol 1998; 100: 600-602.

16. Parker J, Pagliuca A, Kitiyakara T, Whitehead M, Heaton N, OGrady J. Discrepancy between phenotype and genotype on screening for factor $\mathrm{V}$ Leiden after transplantation. Blood 2001; 97: 2525-2526.

17. Graf LL, Welsh CH, Qamar Z, Marlar RA. Activated protein $\mathrm{C}$ resistance assay detects thrombotic risk factors other than factor V Leiden. Am J Clin Pathol 2003; 119: 52-60.

18. Nicolaes GA, Dahlback B, editors. Congenital and acquired activated protein C resistance. Sem Vasc Med 2003.

\section{*Correspondence to}

Mohsen Hamidpour

Department of Hematology and Blood blanking

School of Allied Medical Science

Shahid Beheshti University of Medical Sciences

Iran 